\title{
Historiografia da Guerra do Paraguai
}

DORATIOTO, Francisco. Maldita Guerra: Nova História da Guerra do Paraguai. São Paulo: Companhia das Letras, 2002.

Como já mencionamos em oportunidade anterior², a Guerra do Paraguai é uma temática que tem gerado celeumas na historiografia brasileira (e não somente nesta). $\mathrm{O}$ professor Francisco Doratioto, que atua no Departamento de História da Universidade de Brasília, é conhecido nacional e internacionalmente por pesquisar sobre a Guerra do Paraguai e as relações internacionais entre o Brasil e os países da América Meridional.

Maldita Guerra: Nova História da Guerra do Paraguai, livro publicado pela Companhia das Letras, é fruto de anos de pesquisa do autor e é considerado um referencial para o pesquisador que deseje se aventurar nas tumultuosas águas das Histórias referentes à Guerra do Paraguai. Alguns pesquisadores, contudo, chegam a utilizar irrefletidamente o texto do professor Doratioto como um porto seguro, quase que como um ponto final nas altercações produzidas sobre a historiografia do conflito.

Destacamos aqui a contribuição que o professor Doratioto prestou a historiografia da Guerra do Paraguai, mas não podemos, sob o risco de incorrermos na mais pura ingenuidade, considerá-la como a interpretação mestra que desvendou/iluminou a verdade (Como se algo desta natureza fosse possível) sobre a Guerra do Paraguai.

O próprio professor Doratioto, em momento anterior ${ }^{3}$, chegou a afirmar, inadvertidamente, que a década de 1990 trouxe uma nova luz sobre a Guerra do Paraguai, como se fosse possível que a verdade tivesse finalmente chegado para iluminar os fatos obscuros relacionados a esta temática.

Doratioto é considerado por alguns como o historiador responsável por “desmantelar a

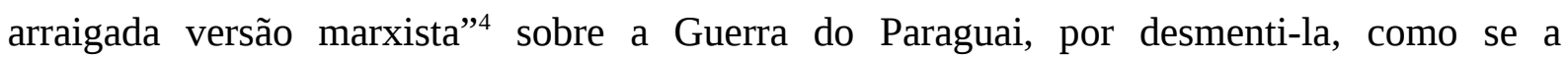

\footnotetext{
${ }^{1}$ Mestre em História pela Universidade Federal da Paraíba (UFPB) e professor do Departamento de Educação da Universidade Federal Rural de Pernambuco (UFRPE).E-mail: andremendes.s@hotmail.com

${ }^{2}$ SALLES, André Mendes. A Guerra Grande no ensino de História. In: SOARES Jr., Azemar dos Santos (org.). Retalhos de História: Culturas políticas e educação no Nordeste do Brasil. João Pessoa: Editora Universitária da UFPB, 2011, p. 131-146.

${ }^{3}$ DORATIOTO, Francisco. Nova luz sobre a guerra do Paraguai. Revista Nossa História, Rio de Janeiro, n.13 Nov. de 2004, p.18-23.
} 
historiografia Revisionista de Pomer e Chiavenato ${ }^{5}$ fosse um engodo, como se não passasse de uma historiografia apaixonada, tendenciosa e mesmo falaciosa. O próprio Doratioto não poupou esforços para assim apresentar a historiografia revisionista.

Doratioto, no intuito de desqualificar a historiografia revisionista, argumenta que esta segue uma perspectiva ideológica e militante. Desta forma, fazemos alguns questionamentos: será que somente a historiografia marxista possui essas características? Será que somente essa corrente historiográfica que é engajada, apaixonada e tendenciosa? Há perspectiva historiográfica que não seja ela mesma ideológica? A historiografia nacionalista de direita não é militante e ideológica? Não seria a historiografia positivista, àquela anterior a revisionista, engajada, preocupada em criar mitos e grandes personagens, em criar heróis e vilões? Não seria a historiografia dita neo-revisionista, uma volta à perspectiva nacionalista (um neonacionalismo?) e, portanto, também ela mesma engajada?

Acreditamos que Francisco Doratioto restaura/revigora, em certo sentido, a historiografia nacionalista anterior ao revisionismo histórico de Pómer e Chiavenatto. Desta forma, o epíteto de neo-nacionalista ou mesmo restauracionista, como denominou Maestri ${ }^{6}$, talvez se enquadre melhor para caracterizá-lo do que neo-revisionista.

Em sua Maldita Guerra, Doratioto, já no primeiro parágrafo da introdução, diz:

Entre 1740 e 1974, o planeta teve 13 bilhões de habitantes e assistiu a 366 guerras de grande dimensão, ao custo de 85 milhões de mortos. O resultado dessas guerras parece ter sido um premio à agressão, pois em dois terços delas o agressor saiu-se vencedor e, quanto a duração, 67\% terminaram em prazo inferior a quatro anos. A Guerra do Paraguai faz parte, portanto, da minoria, pois o agressor, o lado paraguaio, foi derrotado, e a luta se estendeu por cinco anos (p. 17) (Grifo nosso).

Desta forma, Doratioto já deixa bem clara, desde o primeiro parágrafo de sua obra, a sua concepção acerca do conflito. O agressor, quer dizer, o causador da guerra, foi o governo do Paraguai, que invadiu o Brasil, tendo este, inevitavelmente, que retaliar. Portanto, assim entendido o conflito, o governo brasileiro, aquele atingido pela agressão da República

\footnotetext{
${ }^{4}$ Marthe, Marcelo. A Guerra das versões: Um historiador diz que a Guerra do Paraguai não foi bem do jeito que se tem ensinado na escola. Disponível em: http://veja.abril.com.br/030402/p_122.html. Acessado em 01 de fev. de 2012.

${ }^{5}$ POMER, León. A Guerra do Paraguai: a grande tragédia rio-platense. Tradução Yara Peres. São Paulo: Global, 1980; CHIAVENATTO, Júlio José. Genocídio Americano: a Guerra do Paraguai. 18ª ed. São Paulo: Editora Brasiliense, 1983.

${ }^{6}$ MAESTRI, Mário. A guerra contra o Paraguai: História e historiografia: da instauração à restauração historiográfica [1871-2002]. Nuevo Mundo Mundos Nuevos [en línea], colóquios, 2009, puesto en línea el 27 mars 2009. Disponível em: http://nuevomundo.org/index55579.html. Acessado em 20 jul. 2009.
} 
paraguaia, apenas defendeu-se do tirano megalômano que presidia aquele país. Assim, o autor continua advogando em defesa brasileira:

\begin{abstract}
A geração daqueles que lutaram na guerra, quer nos países aliados, quer no Paraguai, não registrava de forma positiva o papel histórico de Solano López. Havia certeza da sua responsabilidade, quer no desencadear da guerra, ao invadir o Mato Grosso, quer na destruição de seu país, pelos erros na condução das operações militares e na decisão de sacrificar os paraguaios, mesmo quando caracterizada a derrota, em lugar de pôr fim ao conflito (p. 19) (Grifos nossos).
\end{abstract}

Além de o autor assegurar a unanimidade em relação a percepção do papel histórico exercido por Solano López entre aqueles que participaram da guerra, algo que, com toda certeza se constitui como improvável e de difícil comprovação histórica, isenta o Império brasileiro de toda a responsabilidade de guerra. Sob uma perspectiva nacionalista, Doratioto aponta López como o responsável, não apenas pelo conflito, mas também, e talvez sobretudo, pela própria destruição do Estado paraguaio e pela dizimação de sua população.

Na visão deste autor, os mortos em combate se constituíram em uma minoria se comparados àqueles que pereceram “devido à fome, doenças ou exaustão decorrente da marcha forçada de civis para o interior, ordenada por Solano López” (p. 456). Para Doratioto, a apresentação deste governante como “ambicioso, tirânico e quase desequilibrado” pela historiografia tradicional "não estava longe da realidade e pode até explicar certos momentos da guerra, mas não sua origem e dinâmica”. (p. 19).

É preciso ressaltar que Doratioto, apesar de pôr em relevo os conflitos regionais relacionados ao processo de construção dos Estados platinos como principal motor da Guerra do Paraguai, retoma muitas das explicações e argumentações da historiografia tradicional, mormente àquelas relacionadas à figura de Solano López.

Outro fator a ser destacado é que Doratioto, assim como fizeram os militares da historiografia tradicional, estabelece o evento do aprisionamento do navio Marquês de Olinda e a invasão à Mato Grosso por forças paraguaias como o marco inicial do conflito. Ao assim proceder, Doratioto, automática e contraditoriamente, desconsidera todos os conflitos anteriores relacionados à Região Platina como possíveis geradores/provocadores da Guerra do Paraguai (como, por exemplo, as intervenções do Estado imperial brasileiro na Argentina e Uruguai).

Torna-se importante destacar, contudo, que Doratioto trata em sua obra das intervenções brasileiras no Uruguai e na Argentina. Contudo, ao estabelecer as investidas 
paraguaias ao Império brasileiro como início do conflito, desconsidera, contraditoriamente, todos os acontecimentos anteriores relacionados/contextualizados à Guerra do Paraguai.

Em relação às intervenções do Império brasileiro nos Estados platinos, Doratioto afirma:

Para viabilizar a intervenção no Uruguai, a diplomacia imperial obteve o beneplácito do governo argentino. Ao promover a entrada de tropas brasileiras no Estado oriental em setembro de 1864, o governo imperial não esperava que o ato gerasse reação contrária significativa. Contudo, Solano López reagiu invadindo o Mato Grosso, em dezembro de 1984, e Corrientes, na Argentina, em abril de 1985 (p. 474) (Grifos nossos).

Na afirmação feita, percebemos que o professor Doratioto entra em contradição com a perspectiva inicialmente exposta por ele: A de que o Paraguai teria sido o país agressor. $\mathrm{Na}$ citação em destaque, a ideia apresentada é a de que o país guarani apenas reagiu às atitudes imperialistas do governo imperial brasileiro. A partir de então, entendemos que assinalar como o marco inicial do conflito o evento do aprisionamento do navio brasileiro Marquês de Olinda e a invasão ao Mato Grosso por forças paraguaias é uma arbitrariedade, isso porque desconsidera toda a política imperialista do Estado imperial brasileiro da segunda metade do século XIX.

Em outro momento, Doratioto diz que “a oposição conservadora apontou como desaconselhável o aumento da extensão das fronteiras brasileiro-argentinas [no que se refere ao Tratado da Tríplice Aliança]”. Diz ainda que a mesma oposição conservadora “[...] indicou que $a$ independência paraguaia estaria ameaçada, pois o país guarani ficaria cercado a leste e a oeste por território argentino, numa espécie de abraço apertado” (p. 474-475) (Grifos nossos).

Questionamos o seguinte: Estando a independência paraguaia ameaçada pelo Tratado da Tríplice Aliança, que fora negociado antes do conflito propriamente dito, como poderia, por exemplo, ser este o país agressor?

Doratioto, ao comentar sobre os eventos que implicaram no aprisionamento do navio Marquês de Olinda e na invasão do Mato Grosso por forças armadas paraguaias, diz “[...] o Império [brasileiro] não declarara guerra ao Paraguai, mas Solano López interpretava ou fingia crer que sim”. Esse autor afirma ainda que Solano López deu a entender “em evidente falsificação, que houvera um ataque brasileiro a alvo paraguaio”. E completa: “O governo 
imperial e a opinião pública brasileira consideraram a captura [do navio Marquês de Olinda] um ato traiçoeiro de Pirataria” (p. 66) (Grifos nossos).

Não obstante Doratioto assinalar que o governo paraguaio entendia como um insulto, ou mesmo um perigo iminente a visita do Marquês de Olinda em águas paraguaias, devido à invasão ao Uruguai, o mesmo considera que López teria fingido tal interpretação, em evidente falsificação. Isso porque, segundo este autor, o governo imperial brasileiro não teria declarado guerra ao Paraguai apenas por invadir o Uruguai.

Entendemos, contudo, que a aliança entre o Uruguai e o Paraguai se constituía como uma forma de equilíbrio de forças na Região do Prata. O império brasileiro, ao realizar a invasão ao Uruguai, rompeu com esse equilíbrio, deixando o Estado paraguaio em situação de vulnerabilidade. Desta forma, diferentemente de Doratioto, não entendemos que a interpretação de López ao considerar que o Estado brasileiro havia-lhe declarado guerra seja um falseamento. A geopolítica da Região platina era muito mais complexa do que a simplificação apresentada por Doratioto.

Enfim, passados exatamente dez anos da publicação de Maldita Guerra, podemos ponderar melhor as suas conclusões/resultados e perceber que existem outras possibilidades para se refletir/pesquisar sobre a Guerra do Paraguai, quer dizer, existem outros caminhos possíveis a serem trilhados que não somente aquele relacionado ao chamado neorevisionismo. 